\title{
UJARAN SALING MEMAHAMI DALAM FILEM NORDIN AHMAD
}

\author{
Aminnudin SAIMON ${ }^{1 *}$ \\ Zaitul Azma Zainon Hamzah ${ }^{2}$ \\ 1,2 Jabatan Bahasa Melayu, Fakulti Bahasa Moden dan Komunikasi, \\ Universiti Putra Malaysia \\ 1aminnudin.saimon@yahoo.com \\ zazh@upm.edu.my
}

Manuscript received 18 Mar 2019

Manuscript accepted 19 May 2019

*Corresponding author

https://doi.org/10.33736/ils.1351.2019

\section{ABSTRAK}

Ujaran saling memahami merupakan hubungan dua hala antara penutur dengan pendengar yang memperlihatkan ujaran penutur dalam menyatakan sesuatu dapat difahami oleh pendengar walaupun ujaran tersebut mengandungi pelbagai bentuk bahasa. Dalam penyelidikan ini, objektif yang terdapat penyelidikan ini ialah menganalisis ujaran saling memahami menggunakan pendekatan pragmatik. Data penyelidikan diperoleh daripada empat buah filem Melayu klasik, iaitu filem Semerah Padi (1956), filem Hang Jebat (1961), filem Seri Mersing (1961) dan filem Lancang Kuning (1962). Hasil penyelidikan ini mendapati, untuk mewujudkan hubungan saling memahami unsur lakuan bahasa dan bentuk bahasa berperanan dalam membantu pendengar memahami ujaran penutur. Bahasa yang melatari sesuatu ujaran dapat diinterpretasi makna sebenarnya berdasarkan kognitif seseorang, faktor lakuan bahasa dan pengetahuan ilmu yang maksimum. Penggunaan teori pragmatik dalam penyelidikan ini ialah Teori Relevans (Sperber \& Wilson, 1986) dan Teori Lakuan Bahasa (Searle, 1969) dilihat amat berwibawa dalam merungkai makna hajat komunikatif penutur, diinterpretasi dan difahami oleh pendengar dan seterusnya mewujudkan hubungan saling memahami.

Kata kunci: Ujaran saling memahami, filem Melayu, lakuan bahasa, teori relevans, pragmatik 


\title{
MUTUAL UNDERSTANDING IN NORDIN AHMAD'S FILMS
}

\begin{abstract}
Mutual understanding is a two-way relationship between the speaker and the listener in that the speaker's utterance in saying something can be understood by the listeners even though the utterances contain various forms of language. This research aimed to analyse the utterances of mutual understanding using a pragmatic approach. The data were obtained from four classic Malay films, Semerah Padi (1956), Hang Jebat (1961), Seri Mersing (1961) and Lancang Kuning (1962). This analysis showed that to establish a mutual understanding, the elements of language and the form of language plays a role in helping listeners understand the utterance of speakers. The true meaning of the utterances can be interpreted based on cognition, the linguistic factor and the maximum knowledge. The use of pragmatic theory, the Relevance Theory (Sperber \& Wilson, 1986) and Speech Acts Theory (Searle, 1969) are seen to be very authoritative in decoding the communicative intentions of speakers, interpreted and understood by the listeners, thus establishing mutual understanding.
\end{abstract}

Keywords: Mutual Understanding, Malay films, speech acts, relevance theory, pragmatics

\section{Pengenalan}

Ujaran merupakan bahasa yang digunakan oleh penutur semasa berinteraksi. Yus (2003) mengatakan bahawa ujaran adalah suatu tindakan yang disertakan dalam ujaran yang lebih khusus, misalnya permintaan maaf, keluhan, pujian, undangan, janji, atau permohonan. Sesuatu ujaran, penutur biasanya berharap maksud komunikatifnya akan difahami oleh pendengar/lawan tutur. Huang (2015) pula mengatakan bahawa ujaran ialah penggunaan satu bentuk bahasa baik kata, perkataan, frasa, ayat atau jujukan ayat oleh seseorang penutur semasa sesuatu peristiwa. Dalam mengungkapkan sesuatu ujaran, tujuan ujaran merupakan salah satu aspek yang harus hadir dalam sesuatu ujaran kerana tujuan ujaran tersebut adalah untuk mencapai suatu hasil yang dikehendaki oleh penutur.

Ujaran saling memahami merupakan ujaran dua hala antara penutur dengan pendengar di mana hajat komunikatif penutur dapat difahami oleh pendengar, walaupun ujaran tersebut mengandungi maklumat linguistik seperti bahasa kiasan, implikatur dan eksplikatur. Spencer-Oatey (2011) mengatakan bahawa ujaran saling memahami ialah bahagian memproses hal yang paling utama, iaitu mengambil alih dalam penerimaan maklumat linguistik. Proses-proses ini mempunyai hubungan yang kompleks dan berbeza dengan anggapan darjah kesedaran dan kawalan. Sesetengah jenis ujaran yang diterima adalah berbeza darjah kesedarannya, iaitu penerimaan secara automatik dan secara automatik tanpa sedar dan di bawah kawalan. Dengan kata yang lebih mudah, ujaran saling memahami ini ialah ujaran yang mengandungi proses-proses yang menghubungkan penerimaan maklumat yang sedia ada dan penerimaan maklumat baharu dalam konteks yang bermakna (Spencer-Oatey, 2010). 
Aspek kejelasan penyampaian sesuatu ujaran yang dihasilkan oleh penutur kepada pendengar perlulah relevan supaya pendengar memahami makna ujaran yang ingin disampaikan. Blakemore (2002) mengatakan bahawa interpretasi ujaran bergantung pada keupayaan pendengar membekalkan tanggapan tentang budaya, kepercayaan, keagamaan, peraturan dan emosi penutur. Walau bagaimanapun, sesuatu ujaran itu sendiri tidak semestinya bersifat eksplisit semata-mata, ujaran bersifat implisit juga banyak digunakan semasa berkomunikasi. Menurut Thomas (1995), ujaran yang diucapkan oleh seseorang penutur itu tidak semestinya mengandungi maksud seperti yang diucapkan (literal or abstract meaning) tetapi kadang-kadang menjangkau kepada makna mengikut konteks (utterances meaning). Grice (1978) pula mengatakan bahawa interpretasi ujaran secara umumnya, dibezakan maksud penutur kepada apa yang diujarkan dan apa-apa yang sebenarnya dimaksudkan (what is said and what is implicated). Dalam hal ini, penentuan makna ujaran amat bergantung pada penggunaannya mengikut konteks kerana konteks wujud dengan kepelbagaian kemungkinan pengertian menurut setiap perspektifnya.

Keberkesanan sesuatu ujaran adalah bergantung pada bentuk linguistik yang digunakan atau disampaikan oleh penutur kepada pendengar. Jika ujaran yang diujarkan tidak difahami oleh pendengar, maklumat atau informasi yang hendak disampaikan tidak berjaya. Perkara ini akan menyebabkan ketidakfahaman atau salah faham yang menyebabkan komunikasi tergendala dan seterusnya menggagalkan komunikasi. Kaur (2010) mengatakan bahawa terdapatnya perbezaan antara "salah faham" dengan "ketidakfahaman", iaitu "salah faham" terjadi apabila pendengar menginterpretasi ujaran atau perkataan dengan makna literal yang ada pada perkataan atau ujaran dan bukannya tujuan atau maksud yang hendak disampaikan oleh penutur, sedangkan "ketidakfahaman" berlaku apabila pendengar gagal untuk memahami makna ujaran atau perkataan.

Hubungan resiprokal saling memahami amat bergantung pada ujaran. Jika ujaran yang diujarkan mengandungi pelbagai leksikal atau makna yang kabur, perkara ini akan memberikan keraguan kepada pendengar untuk memahami leksikal dan seterusnya menyebabkan hubungan saling memahami gagal. Walau bagaimanapun, ujaran berimplikatur sering kali diujarkan oleh penutur disebabkan untuk menjaga maruah seseorang atau untuk menyatakan sesuatu secara tidak langsung, namun ujaran tersebut dapat difahami sekiranya pendengar memahami konteks dan kesan kognisi untuk menginterpretasi ujaran tersebut. Oleh itu, untuk memahami ujaran tersebut, pendengar harus memahami konteks dan memperoleh maklumat yang maksimum semasa berkomunikasi.

\section{Permasalahan Kajian}

Sesuatu komunikasi mempunyai pelbagai tujuan antaranya untuk menyatakan hasrat, menyampaikan maklumat dan memberikan informasi. Komunikasi amat bergantung pada kejelasan leksikal, makna, konteks dan maklumat yang mencukupi. Sesuatu komunikasi akan gagal sekiranya penutur tidak dapat memberikan maklumat yang diperlukan oleh pendengar. Hal ini berdasarkan kenyataan daripada Ishamina Athirah (2015) dan Mustafa Atan (2010) yang mengatakan bahawa sesuatu komunikasi akan berjaya sekiranya penutur memberikan maklumat yang tepat, jelas 
dan berbaloi untuk diproses. Bertitik tolak daripada kenyataan ini, masalah yang timbul dalam penyelidikan ini ialah ujaran saling memahami tidak akan berjaya dicapai sekiranya penutur gagal memberikan maklumat yang tepat, jelas dan berbaloi untuk diproses oleh pendengar, dan pendengar gagal untuk memahami maklumat yang disampaikan.

Selain faktor kognitif, faktor kerelevanan dan kesesuaian leksikal yang digunakan dalam ujaran juga merupakan faktor untuk mewujudkan hubungan saling memahami. Mohd. Shahrizal Nasir (2015) dan Johnson (2012) mengatakan bahawa dalam sesuatu ujaran kosa kata, leksikal, paralinguistik merupakan elemen yang penting dalam menentukan keberkesanan sesuatu komunikasi. Penggunaan kosa kata dan leksikal yang tidak relevan dalam ujaran akan mengakibatkan pendengar memproses maklumat yang salah dan seterusnya menggagalkan komunikasi. Senada dengan itu, masalah yang timbul dalam penyelidikan ini ialah penggunaan kosa kata, leksikal dan paralinguistik dalam ujaran oleh penutur memberikan kesan yang berbeza kepada pendengar sama ada pendengar memahami maksud yang hendak disampaikan atau sebaliknya. Penggunaan kosan kata yang tepat dan relevan dalam ujaran akan memudahkan pendengar memahami dan memproses menjadi maklumat dan seterusnya mewujudkan hubungan saling memahami.

Berdasarkan penyelidikan yang dijalankan oleh Ishamina Athirah (2015), Mohd. Shahrizal Nasir (2015), Johnson (2012) dan Thije (2003) berkisar tentang ujaran dan faktor komunikasi saling tidak memahami berlaku. Penyelidikan yang dijalankan oleh sarjana ini terdapat kelompangan. Oleh hal yang demikian, penyelidikan ini adalah untuk mengisi kelompangan itu dari sudut ujaran saling memahami. Bertitik tolak daripada penyelidikan yang dijalankan oleh Ishamina Athirah (2015) komunikasi antarabangsa tidak akan berjaya sekiranya mengandungi ujaran salah faham atau tidak saling memamhami. Penyelidikan oleh Ishamina Athirah (2015) disokong oleh Johnson (2012) yang mengatakan komunikasi tidak akan berjaya jika komunikator saling tidak memahami. Oleh yang demikian, masalah yang hendak dikaji dalam penyelidikan ini ialah ujaran kurang memahami atau salah faham (misunderstanding) menyebabkan ujaran tersebut tidak difahami dan komunikasi yang berlangsung gagal.

Mustafa Atan (2010) menjalankan penyelidikan yang bertajuk "Implikatur dalam Ujaran Watak dalam Filem Seniman Agung P. Ramlee" mendapati bahawa masyarakat Melayu menggunakan pelbagai bentuk bahasa dalam ujaran-ujaran yang bertujuan untuk menyampaikan mesej atau maksud seperti penyataan yang berlebihan, bahasa sindiran, bahasa kiasan, metafora dan ketidaksesuaian masyarakat konteks. Penyelidikan yang dijalankan oleh sarjana ini memberi ilham kepada penyelidik untuk menyelidik fenomena bahasa dalam filem. Oleh hal yang demikian, penyelidikan yang dijalankan oleh sarjana ini mempunyai kelompangan, iaitu dari sudut ujaran. Bertitik tolak daripada kelompangan inilah penyelidik ingin mengisi kekurangan yang terdapat pada penyelidikan terdahulu. Oleh itu, masalah yang hendak dikaji ialah bidang perfileman sesuai dijadikan bahan kajian seperti yang dijalankan oleh Mustafa Atan (2010), namun penyelidikan dari sudut ujaran saling memahami dalam filem Melayu perlu diteroka dengan meluas. 


\section{Sorotan Kajian}

Kajian yang dijalankan oleh Nor Afiqah Wan Mansor dan Nor Hashimah Jalaluddin (2016) yang bertajuk "Makna Implisit Bahasa Kiasan Melayu: Mempertalikan Komunikasi, Kognisi dan Semantik" mendapati bahawa ketersiratan makna masam, manis, masin dan pahit serta makna yang berasosiasi dengan rasa juga dapat dicungkil dan dikaitkan dengan akal budi penuturnya. Kajian ini merupakan kajian semantik dan akal budi Melayu yang menyelidik mengenai deria rasa masam, masin, manis dan pahit dalam kiasan Melayu. Kajian ini menghuraikan makna implisit dan makna implisit kompleks bahasa kiasan khususnya peribahasa dan kaitannya dengan akal budi Melayu. Kajian berbentuk kualitatif ini mengaplikasikan teori semantik dengan kaedah inkuisitif yang menggabungkan data, teori, kognitif dan falsafah sehingga membawa kepada tafsiran akal budi Melayu. Kaedah inkuisitif dilakukan bagi mencungkil makna sebenar yang ingin disampaikan. Hasil kajian juga mendapati kiasan Melayu mempunyai kaitan yang rapat dengan budaya dan akal budi Melayu. Pengkategorian mengikut medan makna juga membuktikan bahasa kiasan berunsurkan deria rasa tidak hanya memperlihatkan makna teras rasa, malah juga mendukung makna pinggiran lain.

Juma'a Qadir Hussein dan Imran Ho Abdullah (2016) menjalankan penyelidikan yang bertajuk "The Role of Cognitive Context in The Interpretation of Riddles: A Relevance Theory Perspective" adalah untuk mengenal pasti peranan kesan konteks/kognisi dalam menginterpretasi makna teka-teki dalam kerangka TR. Dalam penyelidikan ini, beliau memfokuskan atau mengehadkan pada satu jenis teka-teki, iaitu teka-teki metafora yang dipilih daripada buku "The Language of Riddles" oleh Pepicello dan Green (1984). Berdasarkan dapatan yang diperoleh, teka-teki yang diberi dapat dijawab oleh pendengar dengan menggunakan TR. Hal ini kerana dengan adanya konteks dan kesan konteks yang terdapat pada ensiklopedia penutur dan pendengar memudahkan komunikator memproses maklumat dan memperoleh jawapan dengan mudah. Faktor kesan kognitif/kognisi merupakan elemen yang penting dalam menginterpretasi jawapan teka-teki.

Penyelidikan yang dijalankan oleh Muhammad Zuhair Zainal (2015) yang bertajuk "Makna Ujaran Tak Langsung dalam Skrip Drama Terpilih dari Sudut Pragmatik" mendapati bahawa penggunaan ujaran tak langsung dalam skrip drama terpilih dapat mencerminkan budaya halus dan akal budi tinggi yang dimiliki oleh masyarakat Melayu. Penyelidikan yang dijalankan ini adalah untuk mengenal pasti ujaran tak langsung, menghurai dan menjelaskan makna ujaran tak langsung dalam skrip drama terpilih dengan menggunakan pendekatan pragmatik berdasarkan prinsip makna dalam Interaksi Thomas (1995). Data penyelidikan ini bersumberkan ujaran tak langsung yang terdapat dalam skrip drama terpilih hasil tulisan Mustapha Kamal Yassin dan Usman Awang. Dapatan kajian dirumuskan bahawa penggunaan ujaran tak langsung dalam penulisan skrip drama terpilih mengandungi perlakuan ujaran tertentu dan disampaikan dalam bentuk ayat yang berbeza, iaitu ayat penyata, ayat tanya dan ayat perintah. Ujaran tak langsung yang dikaji mempunyai makna implisit yang dapat difahami makna sebenarnya berdasarkan makna abstrak, makna konteks, makna niat penutur dan interpretasi pendengar. Hasil kajian mendapati penyampaian makna ujaran tak langsung disampaikan secara 
tersembunyi bertujuan untuk bersantun, menjaga air muka seseorang, menjadikan sesuatu bahasa lebih menarik atau kurang menarik, untuk mencapai matlamat yang berbeza dalam satu masa dan untuk menjelaskan niat penutur.

Penyelidikan yang dijalankan oleh Han dan Ni (2015) yang bertajuk "On the Subtitle Translation of Mirror Mirror from Relevance Theory" mendapati bahawa strategi dan peranan TR dapat membantu dalam menterjemah sarikata filem kepada bahasa sasaran. Dalam kajian ini filem yang digunakan ialah filem Mirror Mirror yang dijadikan bahan untuk menganalisis strategi penterjemahan sari kata menurut TR. Terdapat lima strategi yang dikemukakan, iaitu yang pertama menawarkan pengenalan yang ringkas kepada latar belakang penyelidikan dan isu-isu bersamasama dengan strutktur kajian. Yang kedua ialah menyediakan TR dan hubungannya dengan beberapa teori dalam penterjemahan sarikata, manakala yang ketiga ialah memberi tumpuan kepada kajian mengenai strategi penterjemahan sari kata filem Mirror Mirror dari perspektif TR di mana analisis secara terperinci masalah yang sukar dan starategi respon akan dijalankan. Strategi yang keempat ialah kesimpulan dan yang terakhir adalah untuk membuktikan bahawa TR dapat diaplikasikan dalam penterjemahan sari kata untuk menjadi panduan penterjemahan dan memperbaiki kualiti penterjemahan sari kata.

Penyelidikan yang dijalankan oleh Ghazali Lateh dan Shamsudin Othman (2014) yang bertajuk "Tinjauan Interaksi Lisan Bahasa Melayu dalam Kalangan Remaja Malaysia dari Sudut Etnografi Komunikasi" mendapati bahawa aspek kognitif banyak mempengaruhi interaksi lisan sampel kajian. Penyelidikan yang dijalankan oleh sarjana ini memberi fokus kepada bentuk-bntuk bahasa yang digunakan oleh sampel kajian dalam interaksi lisan, kemampuan berbahasa, dan pertimbanganpertimbangan komunikasi dalam perbualan formal. Penyelidikan ini juga membincangkan aspek kognitif yang mempengaruhi interaksi lisan kajian sampel. Perbincangan kedua-dua objektif ini dilaksanakan dalam kerangka teori etnografi komunikasi dan juga TR. Daripada dapatan yang diperoleh, bentuk-bentuk bahasa yang digunakan oleh sampel kajian adalah antaranya pengulangan, penyoalan kembali, penukaran kod, hentian, penggunaan peribahasa, bunyi bukan verbal, penggunaan kata sapaan dan nama rujukan, penggunaan ucap selamat, bahasa Melayu tinggi dan "Dia Orang" sebagai Kata Ganti Diri Ketiga.

Kerelevanan dan perkaitan antara kajian lepas yang dinyatakan dengan penyelidikan ini ialah ujaran yang digunakan dalam kajian-kajian lepas mempunyai perkaitan dengan penyelidikan ini, iaitu ujaran saling memahami. Walaupun kajian lepas tidak menyentuh kepada aspek ujaran salaing memahami, namun penganalisisan, dapatan dan implikasi kajian mempunyai perkaitan dengan penyelidikan ini. Sebagai contoh, kajian yang dijalankan oleh Muhammad Zuhair (2015) menunjukkan bahawa ujaran tidak langsung disampaikan dengan cara yang berbeza dalam ayat yang berbeza. Begitu juga halnya dengan penyelidikan ini, iaitu untuk memperlihatkan ujaran saling memahami berdasarkan konteks, ayat, kosa kata, dan leksikal yang digunakan dalam menyampaikan sesuatu maklumat ataupun hajat komunikatif penutur. 


\section{Metodologi Kajian}

Data utama dalam kajian ini ialah filem Melayu lakonan Nordin Ahmad. Filem yang dijadikan data utama ialah filem Semerah Padi (seterusnya FSP), filem Hang Jebat (FHJ), filem Seri Mersing (FSM) dan filem Lancang Kuning (FLK). Pemilihan filem yang dilakonkan oleh beliau adalah kerana kualiti dan penggunaan bahasanya yang indah dan berpengaruh. Pemilihan filem dibuat adalah antara tahun 1956 hingga 1962. Pada tahun 1956 menerusi FSP nama beliau kembali memuncak menerusi watak utama, iaitu watak Taruna. Pemilihan tahun (1956 - 1962) tersebut dibuat adalah kerana pada tahun tersebut nama beliau dan filem yang dilakonkan membuatkannya kembali bersinar dan memuncak. Daripada 19 buah filem yang dilakonkan sepanjang tempoh tersebut, empat buah filem yang membuatkan namanya terus menyinar dan memberi kesan sehingga kini, iaitu FSP (1956), FHJ (1961), FSM (1961) dan FLK (1962). Pemilihan keempat-empat buah filem adalah berdasarkan sampel daripada populasi filem terkenal yang dilakonkannya dari tahun 1956 hingga 1962.

Penulis telah memfokuskan pemerolehan data, iaitu ujaran saling memahami yang diujarkan dalam watak-watak filem. Pemilihan data ini dibuat adalah berdasarkan ujaran saling memahami akan mewujudkan satu bentuk hubungan resiprokal dan mencerminkan keperibadian seseorang melalui bahasa yang digunakan. Hubungan resiprokal yang wujud membuktikan bahawa ujaran yang wujud, walaupun berdasarkan skrip tetap mencerminkan ujaran saling memahami kerana skrip yang terhasil merupakan manifestasi daripada budaya pengarang itu sendiri. Ujaran saling memahami yang wujud ini termasuklah bahasa kiasan dan implikatur yang diperoleh daripada filem yang dikaji akan dianalisis menggunakan teori Relevans (seterusnya TR) (Sperber \& Wilson, 1986) dan teori lakuan bahasa (TLB) (Searle, 1969). Oleh yang demikian, data dianalisis berdasarkan teori yang digunakan, iaitu menggunakan TR dan TLB. Setiap ujaran yang dipilih akan dianalisis berdasarkan TR yang mengemukakan tiga elemen penting, iaitu Konteks, kesan konteks dan usaha memproses, manakala TLB pula mengemukakan lima paradigmatik, iaitu direktif, asertif, komisif, ekspresif dan deklaratif.

\section{Teori Relevans dan Teori Lakuan Bahasa}

Prinsip relevans lebih menekankan bentuk komunikasi yang dapat difahami antara penutur dengan pendengar (Sperber \& Wilson, 1986). Penutur seharusnya dapat menjamin yang diperkatakan itu benar-benar relevan serta sesuai untuk difahami oleh pendengar. Penutur dapat memastikan yang diperkatakan itu mempunyai ciriciri relevans yang optimum. Relevans yang optimum bermaksud setiap ujaran itu mempunyai kesan konteks yang maksimum yang dapat dirumuskan dalam masa sesingkat. Dengan itu, konteks haruslah seimbang dengan masa memproses untuk menghasilkan kandungan maklumat yang diharapkan (Nor Hashimah Jalaluddin, 2014).

Semasa menyampaikan ujaran, penutur seharusnya bertanggungjawab untuk memastikan ujarannya mengandungi maklumat yang sama dengan perhatian pendengar. Hal ini demikian kerana pendengar akan memberikan perhatian yang relevan pada dirinya. Penutur haruslah memberikan maklumat yang relevan dengan 
penaakulan dan persepsi pendengar dengan memberikan andaian tambahan kepada persekitaran kognitif pendengar (Zaitul Azma Zainon Hamzah \& Ahmad Fuad Mat Hassan, 2011). Terdapat tiga konsep yang penting dalam TR dalam pentafsiran makna, iaitu konteks, kesan konteks dan usaha memproses.

TLB memperlihatkan bahawa bahasa yang dituturkan mempunyai lakuan bahasanya yang tersendiri. Pengertian asas dalam teori ini tertumpu kepada cara menghubungkan makna dan lakuan dengan bahasa. Pengertian ini bertepatan dengan hipotesis Searle (1969) yang mengatakan "bercakap dengan sesuatu bahsa bererti menceburkan diri ke dalam satu bentuk perlakuan yang terikat dengan peraturan". TLB menekankan bahawa pengklasifikasian LB memainkan peranan penting dalam perlakuan komunikasi dan berdasarakan teori ini, komunikasi bukan sahaja bererti perlakuan bagi mendapatkan maksud pengucap, tetapi juga perlakuan bagi mendapatkan maksud atau niat pengucap tersebut terlaksana dan dapat dikenal pasti. Dalam TLB ini, terdapat lima kategori yang digariskan oleh Searle (1969), iaitu asertif, direktif, komisif, ekspresif dan deklaratif.

\section{Dapatan dan Perbincangan}

Daripada keselurahan filem yang dikaji, didapati terdapat ujaran saling memahami yang diperoleh daripada filem Melayu terpilih. Pengungkapan sesuatu ujaran saling memahami dilihat dapat menentukan keperibadian seseorang melalui bahasa yang digunakan, terutamanya bahasa kiasan di samping mewujudkan suasana yang harmoni dalam komunikasi. Pengungkapan ujaran saling memahami bersifat kiasan dilihat dapat memancarkan akal budi bangsa Melayu.

\section{Ujaran saling Memahami Menggunakan Bahasa Kiasan}

Penggunaan bahasa kiasan dalam ujaran saling memahami merupakan satu dapatan yang menarik untuk dikaji. Hal ini demikian kerana dalam ujaran saling memahami kadang kala perkara yang diujarkan mempunyai nilai benar terhadap sesuatu perkara. Dengan menggunakan bahasa kiasan, ujaran yang dilontarkan dapat menyerlahkan keperibadian dan makna sebenar hajat komunikatif penutur. Perhatikan jadual di bawah yang memaparkan ujaran saling memahami menggunakan bahasa kiasan.

Jadual 1

Ujaran saling memahami dalam FSM

\begin{tabular}{|c|c|c|c|c|}
\hline Filem & & & & Ujaran \\
\hline \multirow[t]{4}{*}{ FSM } & D1 & U1 & Malau & Apakah hajat kau? \\
\hline & & U2 & Damak & Saya nak pulang ke Pahang. Itulah hajat saya. \\
\hline & & U3 & Malau & $\begin{array}{l}\text { Jangan pulang, Damak kerana orang-orang } \\
\text { kampung di sini sangat suka kepada kau supaya } \\
\text { tinggal di Mersing. }\end{array}$ \\
\hline & & U4 & Damak & $\begin{array}{l}\text { Saya telah merasai bagaimana pahitnya hidup di } \\
\text { tempat orang. Hujan emas di negeri orang, hujan } \\
\text { batu di negeri saya. Adalah lebih baik di negeri }\end{array}$ \\
\hline
\end{tabular}




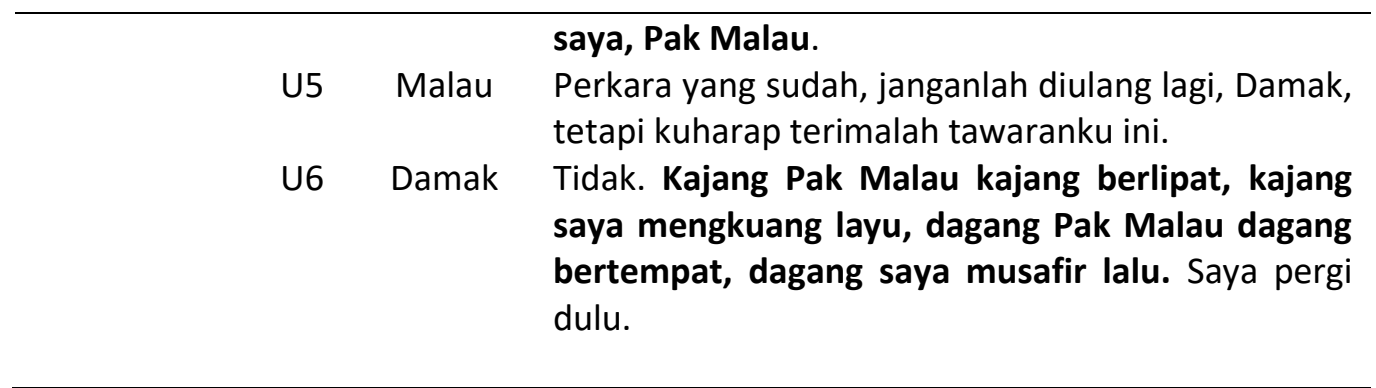

Jadual 2

Ujaran saling memahami dalam FHJ

\begin{tabular}{|c|c|c|c|c|}
\hline Filem & & & & Ujaran \\
\hline \multirow[t]{5}{*}{$\mathrm{FHJ}$} & D2 & U7 & Dang & $\begin{array}{l}\text { Bang Jebat. Janganlah Dang menjadi seumpama } \\
\text { bahtera yang tidak berhaluan, berlabuh tidak } \\
\text { bersauh. }\end{array}$ \\
\hline & & U8 & Jebat & Mengapa Dang berkata begitu? \\
\hline & & U9 & Dang & $\begin{array}{l}\text { Kerana Dang adalah seumpama pokok yang } \\
\text { sedang berputik hanya menunggu masa berbuah. }\end{array}$ \\
\hline & & U10 & Jebat & Apa yang Dang maksudkan? Apa Dang hamil? \\
\hline & & U11 & Dang & $\mathrm{Hmmm}$ \\
\hline
\end{tabular}

Dialog yang diujarkan merupakan ujaran saling memahami yang mengandungi bahasa kiasan. Ujaran saling memahami tersebut tergambar apabila penutur menuturkan sesuatu ujaran dan pendengar memberi respon yang relevan. Sebagai contoh, dalam jadual 1 D1 U4 dan U6, ujaran daripada Damak melalui ujaran "Hujan emas di negeri orang, hujan batu di negeri saya" dan "Kajang Pak Malau kajang berlipat, kajang saya mengkuang layu, dagang Pak Malau dagang bertempat, dagang saya musafir lalu". Ujaran tersebut merupakan ujaran berbentuk kiasan yang menyembunyikan hasrat atau niat penutur daripada berterus terang. Penutur kadang kala sengaja memilih untuk menuturkan ujaran yang mengandungi makna implisit bagi mengelakkan tanggapan negatif pendengar atau untuk tujuan tidak menjejaskan orang lain (Carston, 2010). Ujaran tersebut jika diamati bait-bait perkataan, makna penutur adalah untuk menyampaikan kesedihannya kepada pendengar. Hal ini dapat dilihat pada leksikal yang digunakan, iaitu "Hujan emas di negeri orang, hujan batu di negeri saya" dan "dagang Pak Malau dagang bertempat, dagang saya musafir lalu". Kedua-dua leksikal ini mempunyai makna implisit dalam menyatakan kesedihan penutur.

Leksikal implisit "Hujan emas di negeri orang, hujan batu di negeri saya" merupakan peribahasa yang mempunyai makna susah senang seeloknya di negeri atau di tempat sendiri (Abdullah Hassan \& Ainon Mohd, 2011). Berdasarkan konteks perbualan ini, leksikal ini merujuk kepada kesusahan yang dihadapi apabila merantau ke negeri orang. Pemerolehan makna implisit ini adalah berdasarkan konteks pemula dan andaian awal berdasarkan ujaran penutur, iaitu "Saya telah merasai bagaimana pahitnya hidup di tempat orang". Berdasarkan ujaran awal ini, pendengar tidak mempunyai masalah untuk memahami makna sebenar ujaran dan leksikal tersebut dengan memberi respon yang positif dan relevan. Dengan erti kata 
yang mudah, leksikal tersebut mudah difahami kerana leksikal yang digunakan amat bertepatan bagi merujuk kepada perasaan.

Leksikal "Kajang Pak Malau kajang berlipat, kajang saya mengkuang layu, dagang Pak Malau dagang bertempat, dagang saya musafir lalu" jika dilihat secara literal, leksikal ini merupakan pantun empat kerat, namun jika diperhatikan pada sudut konteks perbualan, leksikal tersebut mempunyai makna yang implisit. Menurut Fatin Rabiha Abdul Kadir dan Zaitul Azma Zainon Hamzah (2017), ujaran tersebut mempunyai makna maklumat konteks pantun tersebut bermaksud atap rumah Pak Malau atapnya berlipat elok dan daripada bahan yang berkualiti, manakala atap rumah Damak dibuat menggunakan mengkuang yang sudah layu berkemungkinan atapnya tidak tahan lama berbanding Pak Malau. Walaubagaimanapun, makna implisit dalam filem tersebut bukan sekadar penerangan mengenai aspek fizikal keadaan atap rumah Pak Malau dan Damak semata-mata, tetapi mencerminkan maksud bahawa Pak Malau dari tempat atau golongan yang elok, baik dan berharta sedangkan Damak digambarkan dari tempat dan golongan yang serba kedaifan dan kekurangan. Dalam erti kata yang lain, Damak merendah-rendahkan martabatnya sebagai seorang perantau dan meninggikan Pak Malau sebagai orang yang berkedudukan di Mersing (Fatin Rabiha Abdul Kadir \& Zaitul Azma Zainon Hamzah, 2017). Berdasarkan andaian awal daripada ujaran terdahulu, pendengar dapat menginterpretasi makna sebenar penutur kerana leksikal yang digunakan amat relevan pada konteks perbualan.

Sperber dan Wilson (1986) mengatakan bahawa implikatur ujaran adalah seperti andaian secara umum mungkin berbeza dari segi kekuatannya. Lebih tinggi kenyataan bersama-sama bagi hajat komunikatif untuk menjadikan nyata beberapa andaian tertentu, lebih tinggi andaian ini dikomunikasikan. Kemungkinan implikatur yang paling kukuh adalah yang premis dan kesimpulan ditentukan sepenuhnya, yang mesti sebenarnya dibekalkan jika interpretasi hendak selaras dengan prinsip relevans, dan yang mana penutur bertanggungjawab sepenuhnya. Implikatur yang kuat adalah yang premis dan kesimpulan, yang pendengar digalakkan dengan kuatnya, tetapi bukan sebenarnya dipaksa untuk membekalkannya. Lebih lemah galakkan, dan lebih lemah implikatur tersebut.

Penginterpretasian dan pemahaman terhadap ujaran yang diterima dipengaruhi oleh faktor LB, konteks, kesan konteks dan usaha memproses. Berdasarkan jadual 1, dalam U1 melalui lakuan direktif, Malau telah mengujarkan ujaran yang memperlihatkan ujaran saling memahami seperti U3 lakuan komisif, dan lakuan komisif dalam U5. Lakuan direktif dalam U1, iaitu "apa hajat kau?" merupakan satu pertanyaan penutur yang disampaikan secara eksplisit dan ujaran ini mudah difahami oleh Damak dalam U2. Ujaran Damak dalam U2 difahami oleh Malau, lalu dibalas oleh Malau melalui ujaran U3 "Jangan pulang, Damak kerana orang-orang kampung di sini sangat suka kepada kau supaya tinggal di Mersing" yang merupakan satu lakuan komisif, iaitu satu penyataan yang mengehendaki penutur melakukan sesuatu pada masa akan datang. Damak yang memahami maksud ujaran Malau telah membalas ujaran Malau melalui U4, iaitu "Saya telah merasai bagaimana pahitnya hidup di tempat orang. Hujan emas di negeri orang, hujan bati di negeri saya. Adalah lebih baik di negeri saya" melalui lakuan ekspresif yang menyatakan sikap psikologis penutur. Walaupun ujaran Damak dalam U4 
berbentuk kiasan, namun dapat difahami oleh Malau apabila Malau melalui lakuan komisif dalam U5 telah mengujarkan "Perkara yang sudah, janganlah diulang lagi, Damak, tetapi kuharap terimalah tawaranku ini". Ujaran Malau dalam U5 difahami oleh Damak lalu melalui lakuan ekspresif, Damak telah mengujarkan, "Kajang Pak Malau kajang berlipat, kajang saya mengkuang layu, dagang Pak Malau dagang bertempat, dagang saya musafir lalu" yang merupakan satu penyataan mengekspresikan sikap psikologis penutur. Urutan peristiwa dan penggunaan bahasa oleh kedua-dua watak dapat memahami kandungan ujaran memperlihatkan penutur dan pendengar mewujudkan hubungan resiprokal saling memahami dalam menyatakan perasaan terhadap sesuatu.

Ujaran Malau (U1, U3, dan U5) dan Damak (U2, 4, dan U6) didapati keduadua penutur dan pendengar mudah memahami mesej yang hendak disampaikan lalu berlangsungnya komunikasi. Maklumat yang disampaikan antara kedua-dua watak selaku penutur dan pendengar ini diproses berdasarkan konteks dan kesan konteks yang melatari perbualan tersebut. Konteks dalam TR adalah pembinaan kognitif secara eksplisit. Konteks ditentukan terlebih dahulu dalam proses pemahaman. Andaian yang dilahirkan secara eksplisit oleh ujaran dilihat sebagai bergabung dengan konteks yang ada dalam minda pendengar pada permulaan lakuan ujaran. Dengan kata lain, konteks merupakan seberkas andaian tentang dunia yang dibina secara psikologi oleh pendengar (Sperber \& Wilson, 1986; 1995). Konteks yang dibina dalam perbualan yang memperlihatkan "ujaran saling memahami" melibatkan andaian tentang budaya dan kepercayaan terhadap pemikiran penutur yang disampaikan menggunakan kiasan, eksplisit dan implisit (Aminnudin Saimon \& Zaitul Azma Zainon Hamzah, 2016).

Menurut Sperber dan Wilson (1986), fakta nyata dimanifestasi kepada individu adalah pada waktu tertentu jika dan hanya jika dia mampu pada masa itu mewakilinya secara mental dan menerima perwakilannya itu sebagai benar atau mungkin benar. Sementara itu, persekitaran kognitif individu adalah satu situasi yang diwujudkan kepadanya, manakala andaian-andaian yang lebih nyata pada individu dalam suatu masa tertentu atau pada saat tertentu adalah fungsi daripada lingkungan fizikalnya di satu sisi dan kemampuan kognitifnya pada sisi yang lain. Hal ini menjelaskan bahawa dalam ujaran saling memahami suatu fakta yang diujarkan oleh penutur dapat dimanifestasikan oleh pendengar berdasarkan lingkungan fizikal dan persekitaran kognitif pendengar itu.

Sehubungan itu, ujaran Malau dapat difahami oleh Damak dan begitu juga sebaliknya kerana Malau sebagai penutur telah membekalkan maklumat konteks untuk ditafsir oleh Damak sebagai pendengar. Dengan berbekalkan maklumat konteks, Malau dan Damak mudah memahami maklumat yang disampaikan kerana maklumat konteks yang terbina dalam ujaran perbualan mereka adalah menyentuh pengalaman yang sudah tercatat dalam ensiklopedia penutur dan pendengar. Tegasnya, dalam ujaran saling memahami, maklumat yang tidak berkaitan dengan persekitaran kognitif sedia ada tidak akan mempunyai implikasi kontekstual, walaupun ia mungkin mempunyai implikasi logiknya sendiri (Aminnudin Saimon \& Zaitul Azma Zainon Hamzah, 2016). Sebaliknya, maklumat yang ada dalam persekitaran kognitif penutur akan menambah maklumat baharu, tetapi maklumat tersebut harus mempunyai hubungan dengan persekitaran sedia ada bagi 
menghasilkan kesan kontekstual yang paling maksimum, termasuklah menafikan, memperkuat, dan memperkaya andaian sedia ada bagi meminimumkan kos proses.

Usaha memproses ujaran berdasarkan jadual 1 adalah minimum kerana konteks dan kesan konteks yang dibina membentuk ujaran saling memahami. Ujaran berkias yang diujarkan dapat diinterpretasi maknanya dengan mudah. Hal ini terpancar pada perbualan dan respon yang diberikan oleh pendengar yang relevan pada konteks perbualan tersebut. Pengetahuan yang luas terhadap unsur alam, persekitaran, budaya dan bahasa Melayu yang melatari sesuatu ujaran seperti yang terdapat dalam jadual 1, memudahkan lagi pendengar untuk menginterpretasi makna sebenar penutur. Usaha memproses menjadi rendah juga dipengaruhi oleh kehadiran leksikal dan maklumat linguistik yang membantu memudahkan pemprosesan ujaran.

Penginterpretasian ujaran saling memahami dalam U4, "Hujan emas di negeri orang, hujan batu di negeri saya. Adalah lebih baik di negeri saya" dan U6 "Kajang Pak Malau kajang berlipat, kajang saya mengkuang layu, dagang Pak Malau dagang bertempat, dagang saya musafir lalu" yang diujarkan dalam bentuk kiasan mudah diproses berdasarkan konteks, walaupun usaha memproses maklumat ujaran ini melibatkan kos proses yang tinggi. Hal ini demikian kerana maklumat linguistik yang disampaikan menggunakan kiasan merupakan maklumat bahasa dan budaya yang telah ada tersimpan dalam ensiklopedia penutur dan pendengar. Justeru itu, ujaran tersebut mudah difahami oleh penutur dan pendengar, walaupun memerlukan kos pemprosesan yang tinggi. Maklumat yang maksimum dapat diterima sebagai relevan, malah telah membantu pendengar untuk menginterpretasi ujaran sehingga memperlihatkan komunikasi antara Damak dengan Malau terus berlangsung dan sekali gus menunjukkan mesej ujaran dapat difahami oleh Damak dan Malau disebabkan adanya maklumat konteks dan kesan kognitif yang melatari komunikasi tersebut dengan kos proses yang minimum. Hal ini sejajar dengan matlamat komunikasi, iaitu untuk meningkatkan lagi persekitaran kognitif penutur dan pendengar.

Jadual 3

Ujaran saling memahami dalam FSP

\begin{tabular}{|c|c|c|c|c|}
\hline Filem & & & & Ujaran \\
\hline \multirow[t]{4}{*}{ FSP } & D3 & U12 & $\begin{array}{l}\text { Bapa } \\
\text { Taruna }\end{array}$ & $\begin{array}{l}\text { Maafkan kami, Penghulu. Kedatangan kami ke } \\
\text { mari ialah untuk mengembalikan sirih adat ini, } \\
\text { tanda putus tali pertunangan dia antara Dara dan } \\
\text { Taruna. }\end{array}$ \\
\hline & & U13 & Penghulu & $\begin{array}{l}\text { Apa artinya ini? Taruna minta dilekaskan, kau } \\
\text { pulak minta diputuskan. Aku tak mengerti. }\end{array}$ \\
\hline & & U14 & $\begin{array}{l}\text { Bapa } \\
\text { Taruna }\end{array}$ & $\begin{array}{l}\text { Penghulu, kami tak mahu membeli buah yang } \\
\text { telah ditebuk tupai. }\end{array}$ \\
\hline & & U15 & Penghulu & Darakah yang kau maksudkan? \\
\hline
\end{tabular}


Jadual 4

Ujaran saling memahami dalam FLK

\begin{tabular}{|c|c|c|c|c|}
\hline \multicolumn{4}{|c|}{ Filem } & Ujaran \\
\hline \multirow[t]{6}{*}{ FLK } & D4 & U16 & Ali & $\begin{array}{l}\text { Saya malu Tok Pawang. Malu kerna kecundang } \\
\text { merebut kasih dan pangkat. Kalau saya tak dapat } \\
\text { biar sama-sama tak dapat. }\end{array}$ \\
\hline & & U17 & Pawang & $\begin{array}{l}\text { Jangan turut nafsu, Datuk. Sekali jerat tak } \\
\text { mengena jangan serik menabur umpan }\end{array}$ \\
\hline & & U18 & Ali & $\begin{array}{l}\text { Membuang masa, umpan habis pelanduk } \\
\text { bertambah liat }\end{array}$ \\
\hline & & U19 & Pawang & $\begin{array}{l}\text { Alangkan desa racun dapat ditabur, takkan silir } \\
\text { pelanduk tak dapat dijinakkan. Tapi, berkehendak } \\
\text { Datuk berusaha sedikit }\end{array}$ \\
\hline & & U20 & Ali & Usaha? Macam mana? \\
\hline & & U21 & Pawang & $\begin{array}{l}\text { Kalau Datuk sanggup mencuri baju dalam Telani } \\
\text { yang masih ada bekas peluhnya, berani hamba } \\
\text { katakan Telani mesti dapat ke tangan Datuk }\end{array}$ \\
\hline
\end{tabular}

D4 dalam Jadual 4 menjelaskan bahawa penutur dan pendengar dapat mencapai hubungan saling memahami berdasarkan ujaran yang disampaikan. Penggunaan bahasa yang melatari perbualan dalam D4 ialah bahasa kiasan. Hal ini dapat dilihat pada ujaran-ujaran seperti D4 U17, "Jerat tak kena jangan serik menabur umpan", D4 U18, "Umpan habis pelanduk bertambah liat" dan D4 U19, "Alangkan desa racun dapat ditabur, takkan silir pelanduk tak dapat dijinakkan". Penggunaan bahasa kiasan dalam perbualan di atas dapat dilihat bagi menyelindungi niat atau cadangan yang jahat. Masyarakat Melayu amat menjaga tutur bicaranya agar tidak menyinggung perasaan orang lain, walhal dalam menyatakan atau mencadangkan sesuatu (Wan Norasikin Wan Ismail, Abdul Latif Samian \& Nazri Muslim, 2017). Penggunaan unsur alam dalam ujaran tersebut menjelaskan bahawa pemikiran masyarakat Melayu amat mementingkan keindahan berbahasa, dan berestetika. Struktur bahasa itu menggambarkan cara penutur memandang dunianya dan bagaimana budaya mempunyai hubungan dengan bahasa (Jufrizal, Zul Amri \& Refnaldi, 2007)

Berdasarkan ujaran U17 "jerat tak kena jangan serik menabur umpan" berkonotasi sebagai satu cadangan kepada pendengar agar tidak berputus asa. Penggunaan leksikal yang tepat dengan konteks menjelaskan lagi maksud ujaran tersebut. Penggunaan "jerat" sememangnya digunakan untuk menangkap binatang dan penggunaan "umpan" pula amat relevan dalam membantu untuk memudahkan lagi penangkapan. Menurut Abdullah Hassan dan Ainon Mohd. (2011), "jerat" bermaksud keadaan yang menyusahkan, manakala "umpan" mempunyai makna modal pemikat. Hal ini bermaksud "jerat" amat menyusahkan bagi binatang yang menjadi sasaran kerana jika terjerat pasti amat sukar untuk terlepas, manakala leksikal "umpan" yang digunakan amat bertepat untuk menjerat mangsa, iaitu dengan menggunakan umpan. Di sinilah ketepatan dan kerelevanan penggunaan leksikal "jerat" dan "umpan" dalam memerangkap sesuatu. Penggunaan leksikal 
"umpan" pula amat berkait rapat dengan "jerat". Hal ini kerana untuk menjerat sesuatu pastinya menggunakan umpan untuk menarik minat binatang dan sebagainya. Penggunaan kedua-dua leksikal, iaitu "jerat" dan "umpan" amat bersesuaian dengan konteks yang menceritakan mengenai kaedah untuk memerangkap mangsa. Dalam konteks ujaran di atas, ujaran tersebut merupakan ujaran mencadang sesuatu kepada pendengar. Penutur mengujarkan ujaran tersebut agar pendengar tidak serik atau berputus asa dalam mengejar sesuatu. Di sinilah kiasan bagi makna mencadang agar tidak berputus asa diterjemahkan.

Dari sudut ujaran, ujaran yang diujarkan oleh penutur dan pendengar mengandungi implikatur dan bahasa kiasan dalam ujaran tersebut. Bahasa kiasan dan implikatur ini terselit dalam ujaran yang digunakan dalam ujaran tersebut. Sebagai contoh, ujaran yang diujarkan oleh penutur, iaitu U16, "kecundang merebut kasih dan pangkat" dan ujaran daripada pendengar, iaitu U17, "sekali jerat tak mengena jangan serik menabur umpan". Kedua-dua ujaran tersebut berkisarkan mengenai hubungan saling memahami, iaitu penutur menyatakan perasaan kecewa dan pendengar bertindak dengan memberikan nasihat dan cadangannya kepada penutur. Ujaran-ujaran kiasan ini secara tidak langsung melambangkan bahasa yang ada dalam pemikiran bangsa Melayu dan daripada bahasa ini menentukan pandangan dunia bangsa Melayu untuk mewujudkan hubungan saling memahami antara peserta komunikasi.

Ujaran "kecundang merebut kasih dan pangkat" yang diujarkan oleh penutur dapat difahami dengan mudah oleh pendengar. Ujaran ini bermaksud bahawa penutur telah gagal dalam mendapatkan cinta dan cita-cita. Abdullah Hassan dan Ainon Mohd. (2002) memberi definisi bagi perkataan "kecundang" ialah gagal, tewas, kalah, kandas, mati dan tidak lulus. Ujaran implikatur yang diujarkan oleh Panglima Ali ini dapat diinterpretasi dengan mudah oleh pendengar kerana pemahaman dan penguasaan leksikal memudahkan lagi pendengar untuk memahami ujaran tersebut. Respon daripada pendengar melalui ujaran "sekali jerat tak mengena jangan serik menabur umpan" merupakan bentuk linguistik bahasa kiasan. Ujaran ini diujarkan bagi tujuan untuk memberi nasihat dan cadangan kepada pendengar agar terus berusaha dalam mendapatkan perkara yang dihajati.

Ujaran saling memahami dalam petikan dialog di atas diteruskan lagi dengan respon daripada Panglima Ali yang masih kecewa dan marah melalui ujaran D4 U18, "umpan habis pelanduk bertambah liat". Daripada ujaran tersebut, jelas menunjukkan Panglima Ali menyatakan rasa kecewa dan marah kerana usahanya untuk memikat Telani sering kali gagal dan menyebabkan hubungan Telani dengan Panglima Yahya bertambah erat. Respon daripada pendengar, iaitu Tok Pawang juga mempunyai ciri-ciri bahasa kiasan melalui ujaran D4 U19, "alangkan desa racun dapat ditabur, takkan silir pelanduk tak dapat dijinakkan". Hubungan saling memahami dalam petikan dialog di atas, jelas menunjukkan bahawa penggunaan dan penguasaan maklumat linguistik yang ada pada peserta komunikasi dapat mewujudkan hubungan saling memahami. Penggunaan bahasa kiasan yang digunakan turut menggambarkan peserta komunikasi mempunyai falsafah, pemikiran dan akal budi yang tinggi dalam bertutur atau berinteraksi.

Dari segi penginterpretasian ujaran, petikan dialog tersebut diinterpretasikan makna ujarannya berdasarkan faktor LB, konteks dan kesan 
konteks yang melatari perbualan tersebut. Berdasarkan LB yang dikenal pasti dalam D4 jadual 4, ujaran D4 U16 mengandungi dua LB yang berbeza, iaitu ekspresif dan komisif. Lakuan ekspresif dapat dilihat pada ujaran "saya malu Tok Pawang. Malu kerana kecundang merebut kasih dan pangkat", manakala lakuan komisif ugutan dapat dikesan pada ujaran selepasnya, iaitu "kalau tak dapat biar sama-sama tak dapat". Ujaran pada D4 U17 menunjukkan LB yang dituturkan mengandungi lakuan direktif menasihati, iaitu pada ujaran "jangan turut nafsu, Datuk. Sekali jerat tak kena jangan serik menabur umpan" dan ujaran D4 U18 yang dilontarkan menunjukkan LB komisif menolak, iaitu melalui ujaran "membuang masa, umpan habis pelanduk bertambah liat" merupakan satu bentuk komunikasi antara penutur dengan pendengar yang menggambarkan hubungan saling memahami apabila penutur menyatakan sesuatu yang mengehendaki pendengar melakukan sesuatu secara implisit dan mudah difahami oleh pendengar yang kemudiannya menolak hajat komunikatif penutur dengan cara implisit. Maklumat linguistik berbentuk kiasan yang terdapat pada D4 U16 - U21 dapat difahami oleh pendengar dengan baik berdasarkan proposisi LB dalam ujaran tersebut.

Berdasarkan D4 dalam Jadual 4, ujaran Panglima Ali (U16 dan U18) dan ujaran Pawang (U17 dan U19) didapati kedua-dua penutur dan pendengar mudah memahami mesej yang disampaikan lalu berlangsungnya komunikasi. Maklumat yang disampaikan antara kedua-dua watak selaku penutur dan pendengar ini mudah diproses berdasarkan konteks dan kesan konteks yang melatari perbualan tersebut. Menurut Sperber dan Wilson $(1986,1995)$ konteks merupakan satu set andaian yang dibina secara psikologis oleh pendengar, manakala Bosco, Bucciarelli, dan Bara (2004) mengatakan bahawa konteks merupakan satu set siri yang menyumbang terhadap pembinaan semula makna yang dihajati oleh penutur dalam hubungan komunikasi. Konteks yang dibina dalam perbualan yang memperlihatkan "ujaran saling memahami" melibatkan andaian tentang budaya dan kepercayaan terhadap pemikiran penutur yang disampaikan menggunakan bahasa kiasan, ujaran eksplisit dan implisit (Aminnudin Saimon \& Zaitul Azma Zainon Hamzah, 2016). Ujaran Ali dalam U16, iaitu "Saya malu Tok Pawang. Malu kerna kecundang merebut kasih dan pangkat. Kalau saya tak dapat biar sama-sama tak dapat" merupakan konteks pemula bagi ujaran saling memahami yang terdapat dalam jadual 4. Andaianandaian awal yang berada dalam kognisi pendengar dapat dilihat pada ujaran yang diujarkan.

Ujaran penutur juga memberikan andaian awal kepada pendengar agar pendengar dapat menginterpretasi melalui penguatan, pengukuhan ataupun pengguguran. Andaian awal pendengar diekspresikan melalui respon ujaran yang didengari. Untuk menjadi relevan dalam konteks, sesuatu andaian mesti dihubungkan dengan konteks tersebut melalui beberapa cara. la menjelaskan intuisi ini dengan mengkhususkan hubungan biasa yang diperlukan. Dakwaan yang konteks untuk pemahaman mengandungi bukan sahaja semua andaian dilahirkan secara eksplisit oleh ujaran terdahulu dalam wacana, tetapi juga semua implikatur bagi ujaran (Carston, 2010). Hipotesis ini diterima benar dalam Jadual 4 di atas yang memperlihatkan ujaran yang dituturkan mengandungi andaian eksplisit dan implisit. Hal ini terpancar dan membuktikan bahawa pendengar memahami ujaran tersebut berdasarkan respon daripada pendengar. Hubungan saling memahami ini berlaku 
disebabkan oleh konteks yang melatari sesuatu perbualan, di samping pendengar memahami latar peristiwa perbualan. Konteks amat bergantung pada latar kebiasaan. Latar kebiasaan ini merupakan dua agen yang mengandungi maklumat, kepercayaan, dan andaian yang sama untuk dikongsi (Adolphs, 2018; Levinson, 2004).

Kesan konteks merupakan faktor yang mempengaruhi dan menentukan penginterpretasian ujaran. Dalam ujaran D4, kesan konteks yang diaplikasikan oleh pendengar berdasarkan faktor pengalaman, ensiklopedia, persekitaran, pandangan dunia, falsafah dan budaya yang terdapat dalam sesuatu masyarakat. Dalam D4, pengukuhan atau penguatan, pengguguran dan penggabungan tidak berlaku kerana pendengar dapat menginterpretasi makna ujaran penutur. Hal ini disebabkan oleh aspek kesan konteks yang diperoleh dan maklumat yang sedia ada terhadap konteks perbualan. Sperber dan Wilson (1986) mengatakan bahawa kesan konteks atau kesan kognitif merupakan andaian awal yang ada pada pendengar tentang maklumat yang relevan dengan diri pendengar. Kesemuanya tercatat sebagai catatan ensiklopedia penutur dan pendengar. Maklumat atau catatan ensiklopedia dalam D4 tergambar melalui ujaran dan leksikal yang diujarkan seperti leksikal "umpan", "jerat", "pelanduk", dan "racun". Penggunaan unsur alam ini sememangnya difahami fungsi dan kegunaannya dalam masyarakat Melayu menyebabkan penutur dan pendengar dapat mewujudkan hubungan saling memahami.

Ujaran Panglima Ali dapat difahami oleh Pawang dan begitu juga sebaliknya kerana Panglima Ali sebagai penutur telah membekalkan maklumat konteks untuk ditafsir oleh Pawang. Dengan berbekalkan kesan kognitif, Panglima Ali dan Pawang mudah memahami maklumat yang disampaikan kerana maklumat konteks yang terbina dalam ujaran perbualan mereka adalah menyentuh pengalaman yang sudah tercatat dalam ensiklopedia penutur dan pendengar. Ujaran yang terdapat dalam D4, iaitu ujaran U16 - U21 merupakan bentuk linguistik kiasan. Ujaran seperti ini menjadi implikatur menurut prinsip relevans adalah disebabkan oleh penutur mesti mengharapkan pendengar melahirkannya, atau sebahagian daripadanya, diberikan bahawa dia menghajatkan ujarannya menjadi relevan secara nyata kepada pendengar. Premis yang diimplikasi mesti dibekalkan oleh pendengar, yang mesti sama ada merujuknya pada memori atau membinanya dengan mengembangkan skema andaian dirujuk daripada memori. Apa yang membuatkan ia munasabah untuk mengenal pasti premis seumpama itu sebagai implikatur adalah bahawa ia membawa kepada interpretasi selaras dengan prinsip relevan, dan bahawa ia adalah secara nyata paling mudah diperoleh untuk melakukannya (Sperber \& Wilson, 1986).

Penginterpretasian bahasa kiasan dalam U16 "malu kerana kecundang merebut kasih dan pangkat", U17, "sekali jerat tak mengena jangan serik menabur umpan", U18, "umpan habis pelanduk bertambah liat", dan U19, "alangkan desa racun dapat ditabur, takkan silir pelanduk tak dapat dijinakkan" yang diujarkan dalam bentuk kiasan dapat diproses berdasarkan konteks, walaupun usaha memproses maklumat ujaran ini melibatkan kos pemprosesan yang tinggi. Hal ini demikian kerana bahasa kiasan yang disampaikan merupakan maklumat bahasa dan budaya yang telah tersimpan dalam ensiklopedia penutur dan pendengar. Ujaran tersebut mudah difahami oleh pendengar dan penutur, walaupun memerlukan kos 
pemprosesan yang tinggi. Pemerolehan maklumat yang maksimum amat membantu pendengar dalam menginterpretasi ujaran sehingga memperlihatkan komunikasi antara penutur dengan pendengar terus berlangsung dan sekali gus menunjukkan mesej ujaran dan hajat komunkatif penutur dapat difahami disebabkan adanya maklumat konteks dan kesan kognitif yang melatari perbualan tersebut dengan kos proses yang minimum.

\section{Implikasi Teori dan Dapatan Kajian}

Ujaran saling memahami merupakan ujaran resiprokal yang diujarkan dalam menyampaikan sesuatu perkara, maklumat atau mengekspresikan perasaan. Ujaran saling memahami ini penting kerana dalam menyampaikan sesuatu maklumat, ujaran yang disampaikan seharusnya difahami dan diinterpretasi dengan baik oleh pendengar agar maklumat yang disampaikan tepat dan diterima. Teori yang digunakan dalam kajian ini ialah TR (Sperber \& Wilson, 1986) dan TLB (Searle, 1969). Kedua-dua teori yang digunakan ini memberikan implikasi yang maksimum terhadap kajian ujaran saling memahami ini. Hal ini demikian kerana dalam TR faktor konteks dan kesan konteks amat memainkan peranan penting dalam menginterpretasi ujaran, manakala faktor TLB pula dilihat sebagai satu bentuk komunikasi yang diujarkan dalam proposisi yang betul untuk memberikan gambaran, penginterpretasian dan memahami ujaran. kedua-dua teori ini memudahkan penutur dan pendengar untuk saling memahami berdasarkan kategori dan faktor yang diberikan seperti faktor konteks, kesan konteks dan kos memproses, faktor asertif, direktif, komisif, ekspresif dan deklaratif yang mempunyai peranan masingmasing dalam mewujudkan hubungan saling memahami.

Implikasi dapatan dilihat amat memberi pengaruh kepada keberkesanan sesuatu komunikasi terutamanya dalam memberikan maklumat. Penginterpretasian yang salah akan menyebabkan maklumat yang diterima dan disampaikan juga salah. Oleh yang demikian, kajian ini memberikan sedikit sebanyak penjelasan mengenai ujaran saling memahami dalam komuniti budaya masyarakat Melayu. Walaupun melalui penggunaan skrip, filem yang digunakan juga memaparkan ujaran saling memahami dilihat sebagai satu bentuk manifestasi terjemahan budaya dan bahasa yang dianuti oleh seseorang pengarah. Kepercayaan, kebudayaan dan ideologi yang ada pada pengarah diterjemahkan dan dimanifestasi melalui skrip yang merupakan wakil daripada pengarah.

\section{Kesimpulan}

Ujaran saling memahami merupakan aspek yang penting dalam mewujudkan komunikasi dua hala. Ujaran saling memahami juga dilihat sebagai satu bentuk bahasa yang digunakan untuk menguji keberkesanan penyampaian maklumat daripada penutur kepada pendengar. Berdasarkan dapatan kajian, ujaran saling memahami merupakan elemen yang paling penting dalam menyampaikan sesuatu maklumat, cadangan, hasrat dan kepercayaan kerana setiap ujaran penutur memberi kesan kepada tindakan pendengar. Setiap ujaran yang disampaikan oleh penutur mempunyai maksud yang khusus dan pendengar sebagai agen kedua dalam komunikasi seharusnya memahami dan memberikan perhatian terhadap ujaran 
yang disampaikan. Faktor penutur juga memainkan peranan penting dalam usaha mencapai hubungan saling memahami kerana setiap ujaran yang diujarkan akan memberi kesan kepada pendengar sama ada berbaloi untuk diproses atau tidak.

\section{Rujukan}

Abdullah Hassan \& Ainon Mohd. (2011). Kamus peribahasa kontemporari (Edisi Ke3). Selangor, Malaysia: PTS Professional \& Publishing Sdn. Bhd.

Abdullah Hassan \& Ainon Mohd. (2002). Tesaurus bahasa Melayu. Selangor, Malaysia: PTS Publications \& Distributors Sdn. Bhd.

Adolps, S. (2018). Corpus and context: Investigating pragmatic functions in spoken discourse (Vol. 30). Amsterdam, Netherlands: John Benjamins Publishing.

Aminnudin Saimon \& Zaitul Azma Zainon Hamzah (2016). Pentafsiran makna dalam ujaran saling memahami. Jurnal Linguistik, 20(2), 33-41.

Blackmore, D (2002). Relevance and linguistics meaning: the semantics and pragmatics of discourse makers. Cambridge, UK: Cambridge University Press

Carston, R. (2010). Metaphor: ad hoc concepts, literal meaning and mental images. Proceeding of the Aristotelian Society, 110, 295 - 321.

Fatin Rabiha Abdul Kadir \& Zaitul Azma Zainon Hamzah (2017). Ujaran implisit dalam filem melayu klasik sri mersing. International Journal of Language Education and Applied Linguistics, 6, 13-24.

Ghazali Lateh \& Shamsudin Othman (2014). Tinjauan interaksi lisan bahasa Melayu dalam kalangan remaja Malaysia dari sudut etnografi komunikasi. Jurnal Pendidikan Bahasa Melayu, 4(1), 30-40.

Grice, H. P. (1975). Logic and conversation. In P. Cole \& J. Morgan (Eds.), Syntax and semantics 3: Speech acts (pp. 41-58). New York, NY: Academic Press.

Han, C. P., \& Ni, X. L. (2015). On the subtitle translation of mirror mirror from relevance theory. American Research Journal of English and Literature, 1(3).

Hantho, A., Jensen, L., \& Malterud, K. (2002). Mutual understanding: A communication model for general practice. Scandinavian Journal of Primary Health Care, 20(4), $244-251$

Huang, Y (2015). Pragmatik (Terjemahan Puteri Roslina Abdul Wahid). Kuala Lumpur, Malaysia: Institut Terjemahan \& Buku Malaysia Berhad.

Ishamina Athirah (2015). Listener pronunciation in misunderstanding in international communication. Southeast Asia: A Multidisciplinary Journal, 15, 26-35.

Thije. J. D. T. (2003). The transition from misunderstanding to understanding in intercultural communication. In L. I. Komlosi, P. Houtlosser, \& M. Leezenberg (Eds.), Communication and culture. Argumentative, cognitive and linguistic perspectives (pp. 197-213). Amsterdam, Netherlands: Sic Sac.

Jankowicz, D., \& Dobosz-Bourne, D. (2003). How are meanings negotiated? Commonality, sociality and the travel of ideas. In J. Sheer (Ed.), Crossing borders, going places. personal constructions of otherness (pp. 122-137). Giessen, Germany: Fischer-Verlag.

Jufrizal Zul Amri \& Refnaldi. (2007). Hipotesis Sapir-Whorf dan struktur informasi klausa pentopikalan bahasa Minangkabau. Jurnal Linguistika, 14(26), 1 - 22. 
Johnson, T. (2007). You said what?! Misunderstanding in im conversation among college students. Unpublished Master's Thesis, Swarthmore College.

Juma'a Qadir Hussein \& Imran Ho Abdullah (2016). The role of cognitive context in the interpretation of riddles: A relevance theory perspective. Pertanika Journal of Social Science and Humanities, 24(S), $11-20$.

Kaur, J. (2010). Achieving mutual understanding in World Englishes. World Englishes, 29(2), 192-208.

Levinson, S. C. (2004). Presumptive meanings: The theory of generalized conversational implicature. Cambridge, MA: The MIT Press.

Mohd. Shahrizal Nasir (2015). Kejelasan dan kekaburan makna kosa kata Arab dalam mahabbah karya Shahnon Ahmad. ISLAMIYYAT, 37(1), 68-75.

Muhammad Zuhair Zainal (2015). Makna ujaran tak langsung dalam skrip drama terpilih dari sudut pragmatik. Unpublished PhD Thesis, Universiti Putra Malaysia.

Mustafa Atan (2010). Implikatur dalam ujaran watak dalam filem Seniman Agung $P$. Ramlee. Unpublished PhD Thesis, Universiti Putra Malaysia.

Nor Afiqah Wan Mansor \& Nor Hashimah Jalaluddin (2016). Makna implisit bahasa kiasan melayu: Mempertalikan komunikasi, kognisi dan semantik. Jurnal komunikasi. Malaysian Journal of Communication, 32(1), 189-206.

Nor Hashimah Jalaluddin (2014). Pemartabatan Bahasa Melayu: Mengenali falsafah bahasa Melayu. Selangor, Malaysia: Institut Alam dan Tamadun Melayu

Searle, J. R. (1969). Speech acts: An essay in the philosophy of language. New York, NY: Cambridge University Press.

Spencer-Oatey, H. (2011). Achieving mutual understanding for effective intercultural management. Retrieved from http://www2.warwick.ac.uk/fac/cross_fac/ globalpeople/resourcebank/researchpapers

Spencer-Oatey, H (2010). Intercultural competence and pragmatics research: Wxaming the interface through studies of intercultural business discourse. In A. Trosborg (Ed.), Handbook of pragmatics (pp. 189-216). Berlin, Germany: Mouton de Grayter

Sperber, D., \& Wilson, D. (2002). Truthfulness and relevance. Mind, 111, 583-632.

Sperber, D., \& Wilson, D. (1995). Relevance communication and cognition (2nd ed.). Cambridge, UK: University Press.

Sperber, D., \& Wilson, D. (1986). Relevance communication and cognition. Cambridge, UK: University Press.

Thomas, J (1995). Meaning in interaction. London, UK: Longman

Wan Norasikin Wan Ismail, Abdul Latif Samian \& Nazri Muslim (2017). Bird element symbolism in malay proverbs. International Journal of Asian Social Science, $7(2), 119-125$.

Yus, F. (2003). Humor and the search for relevance. Journal of Pragmatics, 35(9), 1295-1331

Zaitul Azma Zainon Hamzah \& Ahmad Fuad Mat Hassan (2011). Bahasa dan pemikiran dalam peribahasa Melayu. GEMA Online ${ }^{T M}$ Journal of Language Studies, 11(3), 31-51. 